Purdue University

Purdue e-Pubs

LARS Symposia

Laboratory for Applications of Remote Sensing

$1-1-1975$

\title{
Determination of Groundwater Inflow to Prairie Lakes Using Remote Sensing
}

J.M. Whiting

Follow this and additional works at: http://docs.lib.purdue.edu/lars_symp

Whiting, J. M., "Determination of Groundwater Inflow to Prairie Lakes Using Remote Sensing" (1975). LARS Symposia. Paper 61. http://docs.lib.purdue.edu/lars_symp/61

This document has been made available through Purdue e-Pubs, a service of the Purdue University Libraries. Please contact epubs@purdue.edu for additional information. 
Reprinted from

Symposium on

\title{
Machine Processing of Remotely Sensed Data
}

\author{
June 3 - 5, 1975 \\ The Laboratory for Applications of \\ Remote Sensing \\ Purdue University \\ West Lafayette \\ Indiana \\ IEEE Catalog No. \\ 75CH1009-0 -C \\ Copyright (C) 1975 IEEE
}

The Institute of Electrical and Electronics Engineers, Inc.

Copyright (C) 2004 IEEE. This material is provided with permission of the IEEE. Such permission of the IEEE does not in any way imply IEEE endorsement of any of the products or services of the Purdue Research Foundation/University. Internal or personal use of this material is permitted. However, permission to reprint/republish this material for advertising or promotional purposes or for creating new collective works for resale or redistribution must be obtained from the IEEE by writing to pubs-permissions@iee.org.

By choosing to view this document, you agree to all provisions of the copyright laws protecting it. 


\section{J. M. Whiting}

Saskatchewan Research Council, Saskatoon, Saskatchewan Canada.

\section{ABSTRACI}

This study was designed to find the locations in Big Quill Lake, Saskatchewan, where the transfer of surficial and aquifer groundwater occurs in the lake bed. Using the findings of a geological survey done between 1966 and 1969, and combining the results of the remote sensing techniques of ERTS, airborne radio phase detection (E-PHASE) and infrared line-scanning, it proved possible to locate nine areas at which inflow of groundwater is assumed to take place. Together these nine locations comprise an area of four square kilometers $\left(1.5 \mathrm{mi}^{2}\right)$ in a lake that covers 250 square kilometers $\left(100 \mathrm{mi}^{2}\right)$. In addition it was possible to separate these nine groundwater locations from such dynamic events as spiral currents (a tenth anomaly zone) and peninsula building botton currents.

\section{INTRODUCIION}

This study was undertaken or the Federal Government of Canada under a Department of Supply and Service contract (KW 111-2-1077) for the Canada Centre for Inland Waters. The ERIS satellite and infrared line scaming information were supplied by the Canada Centre for Remote Sensing. The E-PHASE or radio wave phase detection was conducted under contract by Barringer Research Ltd. in conjumction with the Saskatchewan Department of Highways.

The research was conducted on Big Quill Lake (Figure I) which is at the centre of an internal drainage system of surface water and is situated in an Aspen Parkland natural vegetation zone. The lake is very shallow - its depth does not exceed three meters (10 feet) and yet it is relatively large $\left(250 \mathrm{~km}^{2}\right.$ or $\left.100 \mathrm{mi}^{2}\right)$. The area of its internal drainage basin is approximately 2700 square kilaneters $\left(1000 \mathrm{mi}^{2}\right)$. The water of Big Quill Lake is saline reaching a concentration of $81,000 \mathrm{mg} / 1$ below the ice in the winter. The dissolved solids are mainly sodium and magnesium sulphates.

The purpose of the ongoing study, which started in 1965, was to accumplate data on the resources of the lake and in particular to determine the hydrological and chemical balance of the lake and basin in order to establish the value of the lake in terms of recreation, wildlife, fishing, domestic, agriculture, and salt recovery.

The study thus far has shown that groundwater inflow is an inmortant component in the hydrological balance of the lake, and that the water balance cannot be accurately predicted by the use of meteorological and surface drainage data alone. Although by deduction, an estimate can be made about the probable relative quantity of groundwater inflow during a particular year, in order to meet the main objective of the study it is necessary to obtain direct measurements on the behaviour of the groundwater aquifers. A drilling survey which was conducted between 1966 and 1969 (Christiansen and Meneley 1967, 1971) indicated in a general way that the local Big Quill Lake aquifer must be integrated in a very complex regional aquifer system and also connected to a buried preglacial river valley covering 3 provinces (Christiansen, 1971) and also that these local aquifers probably underlie only the southern half of the lake.

\section{THE DEMARCATTON OF THE AREAS}

\section{OF GROUNDWATER INFLOW}

The mineral composition of the water in Big Quill Lake implies that there is a persistent groundwater discharge to the lake, although it has been shown statistically that this discharge is not continuous, nor does the amrual inflow have to balance the annual outflow (Whiting, 1975). It has been estimated that the amnual amount of groundwater transferred from the aquifers to the lake can be as high as 30 percent of lake water amually lost by evaporation. In order to determine the amount of water which is ammally discharged from the aquifers, the location of the aquifers must be known. Since it is expensive to use a grid drilling program to find the inflow locations it was decided to use geophysical methods to pin point the locations. The subsequent study is the basis for this paper. 
The E-PHASE resistivity survey was conducted by Barringer Research Ltd. of Toronto in conjumction with the Saskatchewan Department of Highways. The Barringer System uses radio waves which are broadcast by existing transmitters, for example, commercial AM stations. The E-PHASE resistivity survey technique is based on wave tilt measurements. The degree of forward tilt of the vertical electric field vector is a function of the resistivity of the earth down to a distance of the skin depth penetration of the radio waves. From the magnitude of these resistivity values, the nature of the surface and subsurface material can be inferred. Dry, granular sediments yield high resistivity values, whereas waterlogged sediments, being good conductors of electricity, will have low resistivity values. The technique uses three frequencies, very low frequency (VLF) at $18.6 \mathrm{KHz}$, low frequency (LF) at $368 \mathrm{kHz}$, and broadcast band $(B C B)$ at $600 \mathrm{KHz}$, thereby allowing three different skin depth penetrations to be made to give inferences on the type and the thickness of certain layers. In particular, the survey was to detect sand and gravel strata.

There are some limitations in this techique (Whiting, 1975), but the most important in the case of Big Quill Iake is the irrelevant background noise caused by the attenuation of the signal by the highly saline water. In order to learn whether in fact the E-PHASE survey had managed to receive geologic noise of significance from the surface level or from below the surface, geologic and physiographic ground true data were compared qualitatively. The sursurface sediments found in 18 auger holes which coincided with the ten flight 1ines, Figure 2, were compared to the E-PHASE resistivity and apparent skin depth penetration. All holes were found conductive except one in which the E-PHASE did not show the sand and gravel. This may have been due to the thimess of the sand and gravel and/or to the cover of more conductive sediments or to a more conductive layer of water.

In the comparisons to physiographic features, the E-PHASE profiles matched the topographic bottorn contours (Figure 2) and such land features as islands, peninsulas, raised beaches, glacial spillways, old stream chamels and salt beds even when buried. A comparison was made between the resistivity and skin depth penetration detected over land and over water. The comparison showed that over water the depth penetration was shallower, reflecting the shielding effect of the water. Penetration dropped by 50 percent in the $\mathrm{VLF}$ frequency and by 25 percent in the BCB frequency. The skewness and kurtosis (Figure 2) show that sharp peak anomalies occur in both bands above the small mean values. In other words, these peaks are statistically significant and should not be considered as noise. Anything more than 3.6 meters ( 11.8 feet) skin depth in VLF and 1.2 meters ( 3.8 feet) in the $B C B$ would be significant. The only significant result of this survey by itself was the discovery that below the southem shore at some depth either an impervious clay layer may be present or that intrusion of low resistivity water either to or from the lake occurs.

\section{FINDINGS FROM ERTS SURVEY}

ERTS was lannched in July, 1972 by NASA in the United States of America. Within days pulses broadcast by the satellite were received by the Prince Albert Satellite Station (PASS) in Canada using data supplied by NASA. The station has a "quick-look" facility which produces uncorrected prints in two of the four bands received in Canada. The analog reception tapes are sent to Ottawa and translated into digital tapes which are then available to research organizations, generally within three months. On the computer tapes (CCI) each scan line consists of 3600 data pulses. The pulses are called pixels. A pixel represents the reflected light intensity of a ground area of approximately 60 by 90 meters. The reflected light intensity values are divided in 64 digital steps. A cauputer program was written for an IBM 370 model 158 computer in Assembler and Fortran to translate the $O C R S$ PDP-15 40 bit words into IBM integer format. No attempt was made to transform or to calibrate the data although now that procedures are available, this could be done.

In this survey, both photographic frames and OT ERTS frames were used. It was decided in advance that analysis would be made only where photographic density changes occurred and where these areas matched the E-PHASE findings (Figure 2) and where related to the geology drilling program. In contrast to the latter two survey techiques, the ERTS senses only the surface characteristics, and these only in terms of different degrees of reflected light intensities. Therefore, it was necessary to use an indirect indicator, which would reveal the presence of upwelling groundwater. It was thought that algae could serve as an indicator as the groundwater areas would provide a more favourable enviromment for algal growth. It was further theorized that the greater density of algae would affect the reflected light in such a mamer as to be detectable by ERTS at the scale of $1: 26,000$.

There are some limitations inherent in this as inferred results are not as good as direct observations. Secondly, the magnitude of the groundwater inflow may be too small, or the inflow may be too dispersed to produce an area of lower salinity. Thirdly, the temperature of the groundwater may not be advantageous to algal growth which may outweigh the advantage of lower salinity campared to the remainder of the lake.

Fram 24 photographic images, persistent photographic density patterns were plotted (Figure 2) and compared to the E-PHASE. Of the ten centres of high photographic density, nine were staionary, while one located at the north east peninsula appeared to be dynamically controlled or wind-induced. Two fronts or sharp 
density changes occur north of the centre southern peninsula. Maps, at the scale of 1:50,000 and $1: 26,000$ in each band were produced showing quantitative light intensity using the computer compatible tapes (OCT).

The 1:50,000 ERTS quantitative map was constructed using a computer program to physically match it to a Canadian National Topographic Series 1:50,000 map. This was accomplished by averaging first 2 pixels and then 3 pixels alternatively along a scan-line. Then adding each of these average values to the next scan-line in the same mamner. The averaging routine was restarted every second line. A line print was then made at 8 lines to the inch. For colour composite maps, the program picks 5 prominent levels from the histogram of reflectivity intensities. These levels generally consisted of about 5 numbers or intensities. For publication purposes, these maps were photo-mechanically reduced. The $1: 26,000$ scale map is a line print of each pixel printed at 6 lines per inch in vertical colums of 120 pixels.

Theoretical values of turbidity and chlorophyll, based on the work of Bukata (1974), can be applied to these maps (Figures 3 and 4) thereby giving relative turbidity and chlorophyl1. These calibration graphs have been transposed from Lake Erie'so the values are not absolute for Big Quill Lake and are only relative to allow physical interpretations. To allow these graphs to be used it is necessary to prove that whatever is creating the dark anomalies or low reflectance areas (CCT) is not saturating all ERTS bands or causing cross-talk. A pixel by pixel cross correlation program was witten to analyze 6 different tapes for independence between bands.

If the correlation graph of Bukata in Figure 3 is correct, then the ten anomalies cited are due to the lack of turbidity and in Figure 4 are due to the lack of chlorophyll. One of the anomalies is caused by dynamic events since it is not always present and when it is, its frequency distribution from the cross correlation program between MSS 1 and MSS 2 always has two nodes, whereas the remainder are only binodal when atmospheric disturbances such as strong winds, cloudy conditions or fog occurs.

To aid in interpretation, two consecutive days were thematically mapped in five colour intervals. Two of these intervals are shown in both Figure 3 and 4 . These intervals were chosen in each case to differentiate between the intensity of the major portion of the lake compared to the area with the least turbidity or the least amount of chlorophyll. This means that ERTS is detecting water at the surface which is not native to the lake and which is not associated to atmospheric events, but is in fact upwelling groundwater. Therefore, it was the absence of algae that indicated groumdwater upwelling.

With this discovery, it can now be stated with certainty that the radiowaves received by the E-PHASE survey must have penetrated to the bottom in these ten locations, because there the shielding effect of saline water is not present. In other words, the ten areas on ERTS and the major zones of significant resistivity values are coincident, Figure 2 .

\section{AIRBORNE INERARED LINE-SCANNING SURVEY}

The surface water temperature map shown in Figure $5 \mathrm{a}$ presents the results of the fourth attempt to find the groundwater uwwelling locations. The theory was that the survey would show areas of groundwater upwelling as cold surfaces during the summer. It was preferred at the inception of the study to use Nimbus $\mathrm{E}$ or NOAA-2. however, it transpired that these were not available as computer tapes.

The temperature map (Figure 5a) was constructed using an analogue couputer at the Canada Centre for Remote Sensing (CCRS), Ottawa, to density slice only the water areas. This represented one third of the full scale of six possible isolevels. The scan lines were calibrated using an onboard PRT-5 in conjunction with a photometer along a NADIR trace line to give absolute temperatures. This map shows the same nine groundwater inflow areas inferred from the ERTS data. Some stream inflow areas also show up as being colder than the lake. Two zones of warmer water, $16^{\circ} \mathrm{C}$ stripes, are in line with the prevailing wind direction, with some curvature, as they are part of a spiral. The warmer water could be caused by algae which increase the water temperature by absorbing solar radiation (Strong, 1974), or by groundwater from a deeper aquifer. The known aquifers at a depth of 12 to 15 meters and at 45 meters are ruled out because the nomal gradient of $0.5^{\circ} \mathrm{c} / 30$ meters would not raise the temperature to $16^{\circ} \mathrm{C}$ from a temperature of 5 or $7^{\circ} \mathrm{C}$ at 30 meter depth, unless heated by exothermic reaction with a salt bed.

By combining the results of the geological drilling survey, the E-PHASE survey, the ERTS findings, and the airbome infrared survey, it can be stated that in all probability there are nine locations at which inflow of groundwater occurs. These locations from 6 ERTS frames cover on the average an area of approximately 4 square kilometers ( $1.5 \mathrm{mi}^{2}$ ). It should be stressed that by themselves none of these survey techniques give sufficient data from which to infer inflow of groundwater from aquifers into the lake at particular locations. The final proof that these nine locations are indeed the areas at which groundwater occurs can only be given by drilling into the lake bed at these locations and physically measuring the flow, its temperature, and rate of diffusion.

\section{SOIL EROSION AND DELTA BUILDING}

The recent work by Bukata (personal commmication) on the mirror image erosion of Point Pelee and Long Point on Lake Erie appears to be 
relevant to Big Quill Lake. It was found that erosion and deposition is only obvious on infrared imagery at two peninsulas on the west side (labelled A and B in Figure 5a). Comparison between Figures $5 \mathrm{a}$ and 3 (Turbidity) shows that an area of cold water between the two peninsulas, $G$, is an area of increased turbidity. This shows that bottom water is upwelling. Upwelling is also occurring offshore from the two peninsulas at $\mathrm{F}$ and $\mathrm{H}$. Since the three areas of assumed groundwater (points C, D and E) are offshore from these three shore effects (F, G and H), it is possible that the six zones are related dynamically. The bottom current would carry the colder groundwater to shore, creating two persistent cold areas (one above the source and one at the shore). It is also interesting to see how remarkably similar the dynamics shown in Figure $5 \mathrm{~b}$ are to the surface temperatures shown in Figure $5 \mathrm{a}$.

\section{CONCLUSION}

Using three remote sensing surveys and computerized techniques nine groundwater sites have been found. Differentiation has been made between the groundwater upwelling locations and a dynamic spiral induced offshore from a peninsula. The erosion and deposition of material between two mirror image peninsulas has also been shown. What is now needed is to be able to quantify the results using ten groups, each with two consecutive days to measure the diffusion under different atmospheric conditions, and, therefore, measure the diffusion using remote sensing.

\section{REFERENCES}

Barringer Research Ltd., 1973. Report on Multifrequency E-PHASE Airborne Resistivity Surveys over Big Quill Lake and Estevan Coal Field Areas; Toronto.
Bukata, R. P. and Brutan, J. G., 1974(a). The Application of Telemetered ERTS Data to Lake Research. Paper $\# 25$. Second Canadian Remote Sensing Conference, Guelph.

\section{4(b). ERTS-1 Digital Clasification} of Water Regimes Comprising L. Ontario. Paper 非3. Second Canadian R. S. Conf. Guelph.

and Haras, W. S., 1974(c). Space Observations of Lake Coastal Processes in L.

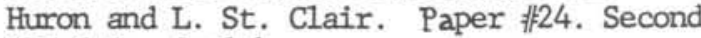
C.R.S.C., Guelph.

Christiansen, E. A., 1971. Geology and Groundwater Resources of the Wynyard Area (72P), Map no. 10 (Revised Edition), Geology Division, Saskatchewan Research Council, Saskatoon, Saskatchewan.

Meneley, W. A., 1967. Geology and Groundwater Resources of the Melfort Area (73A), Map no. 6, Geology Division, Saskatchewan Research Council, Saskatoon, Saskatchewan.

McNeill, J. D., Jagoditis, F. L., Middleton, R. S., 1973. Theory and Application of the E-PHASE Airborne Resistivity Method, Symposium on Electromagnetic Exploration Methods, Univ. of Toronto and CEGS.

Strong, E., 1974. Remote Sensing of Algal Blooms by Aircraft and Satellite in L. Erie and Utah L., Remote Sensing of Envirorment, No. $3,99-107$.

Whiting, J. M., 1975. Evaluation and Interpretation of ERTS Imagery for Big Quill Lake, Saskatchewan Research Council Report E 75-3, Saskatoon.

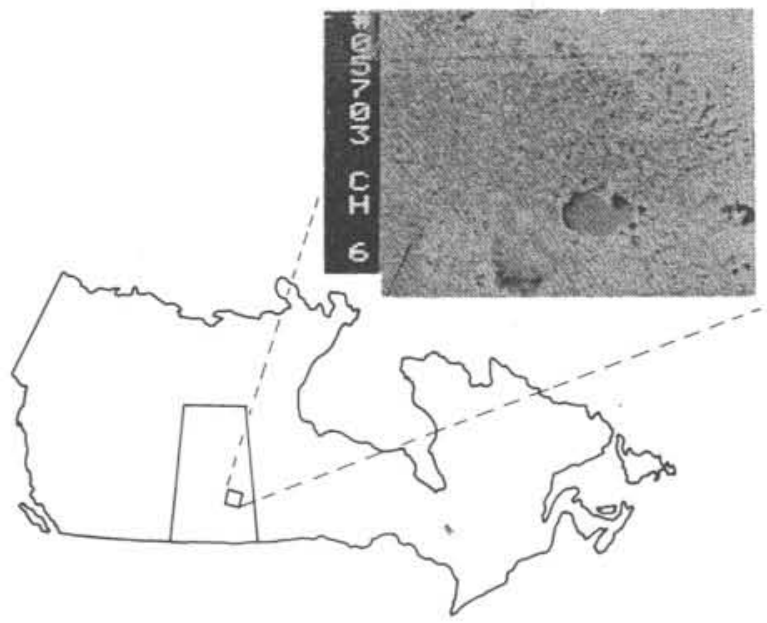

FIG. I SASKATCHEWAN, CANADA

Location of the Quill Lakes Using an ERIS Photo in MSS 2 (Channel 6) for September 6, 1973 


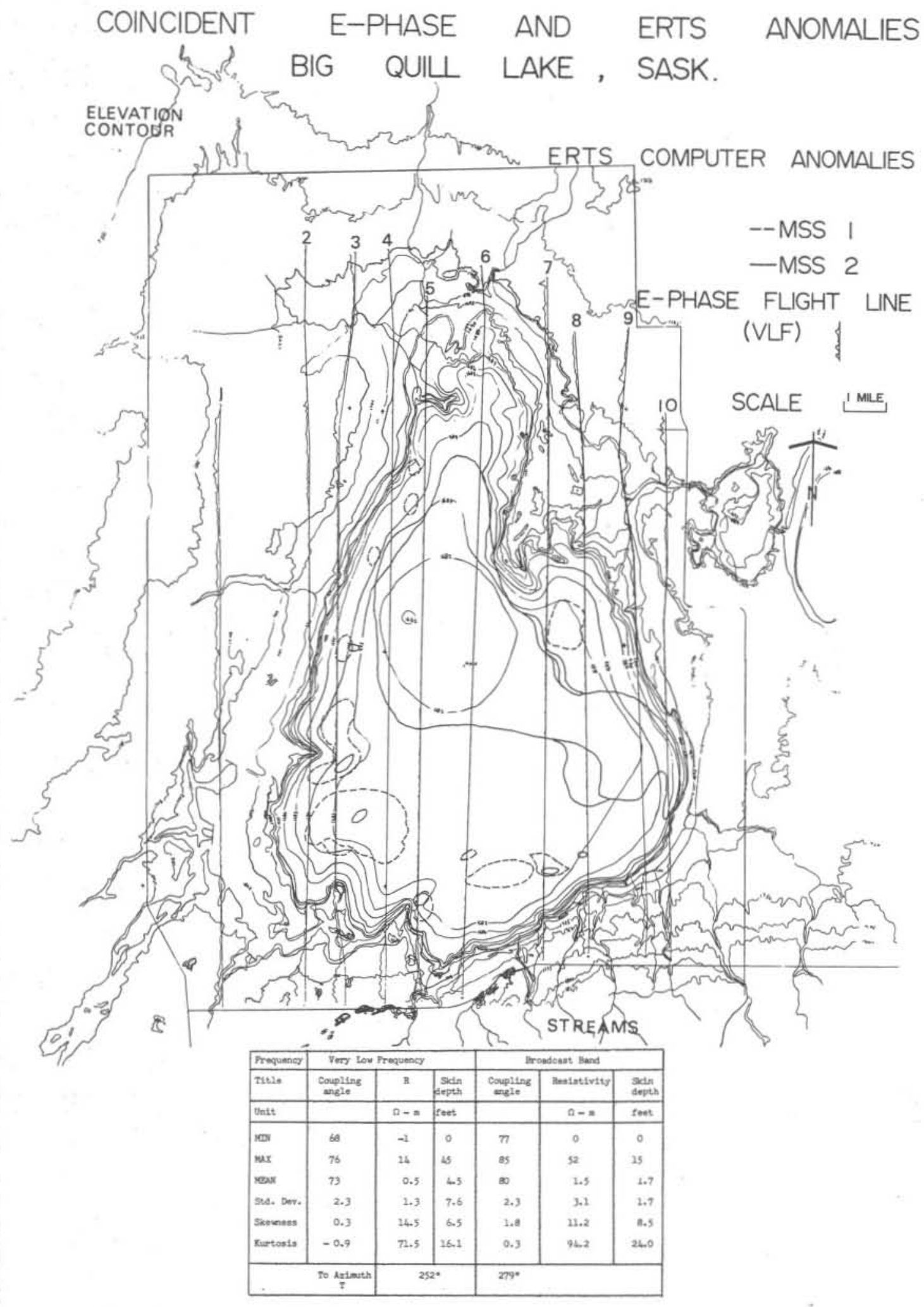

Fig. 2. Electric Field Flight Lines Over The Zones of Groundwater Inflow.

The table shows the range of values of the E-PHASE flights over the water only. The map shows the areas of higher skin depth penetration are coincident with the ERTS anomalies. 

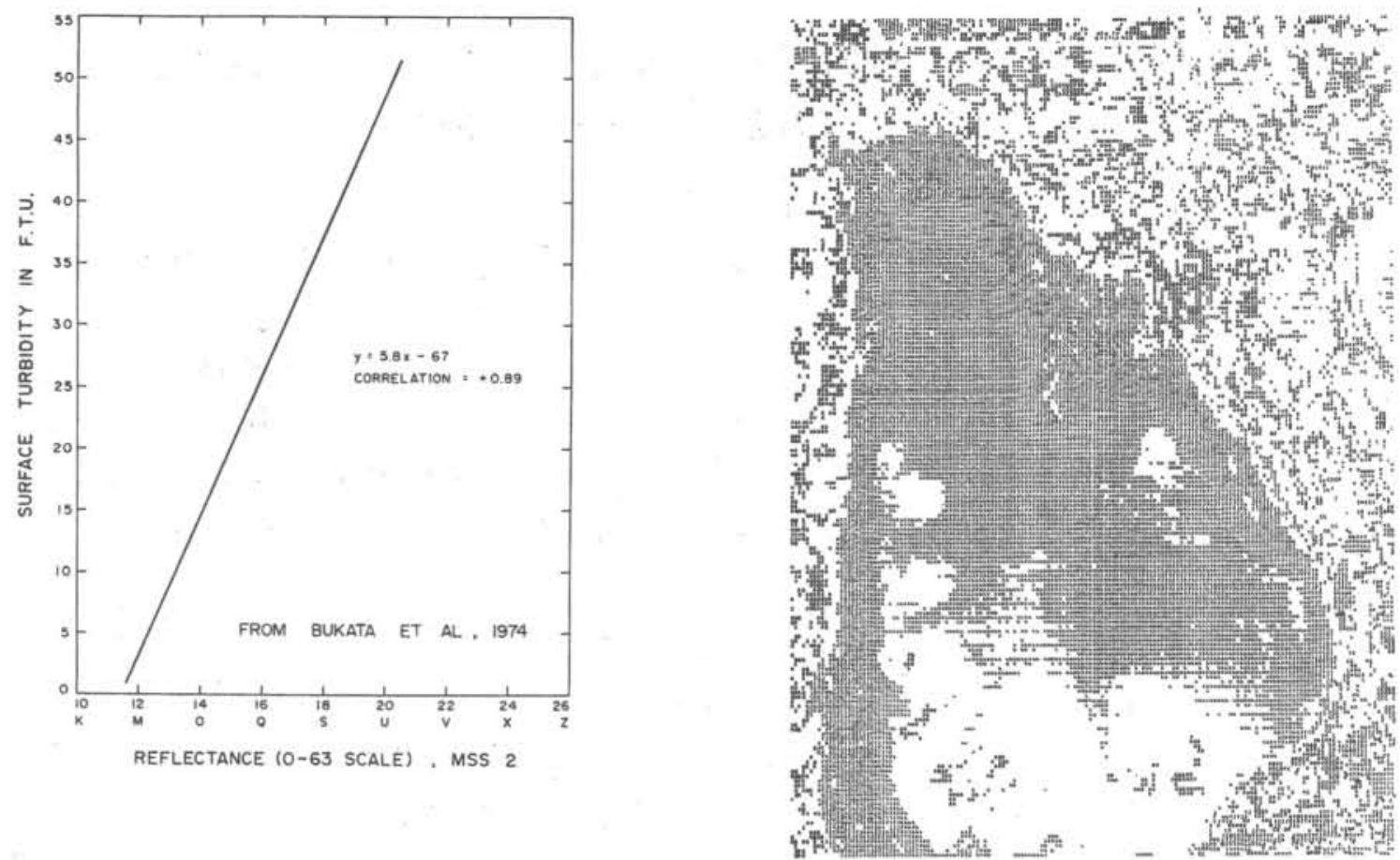

Fig. 3. Relative Measurements of Turbidity, September 5, 1973. Transposing an example from Lake Erie, the CCT map of quantative turbitity was produced showing the major portions of the lake with high turbidity with pockets of little turbidity. At the centre of some of these low turbidity pockets the lowest value is $Q$ and R. (FTU - Formazin Turbidity Units)
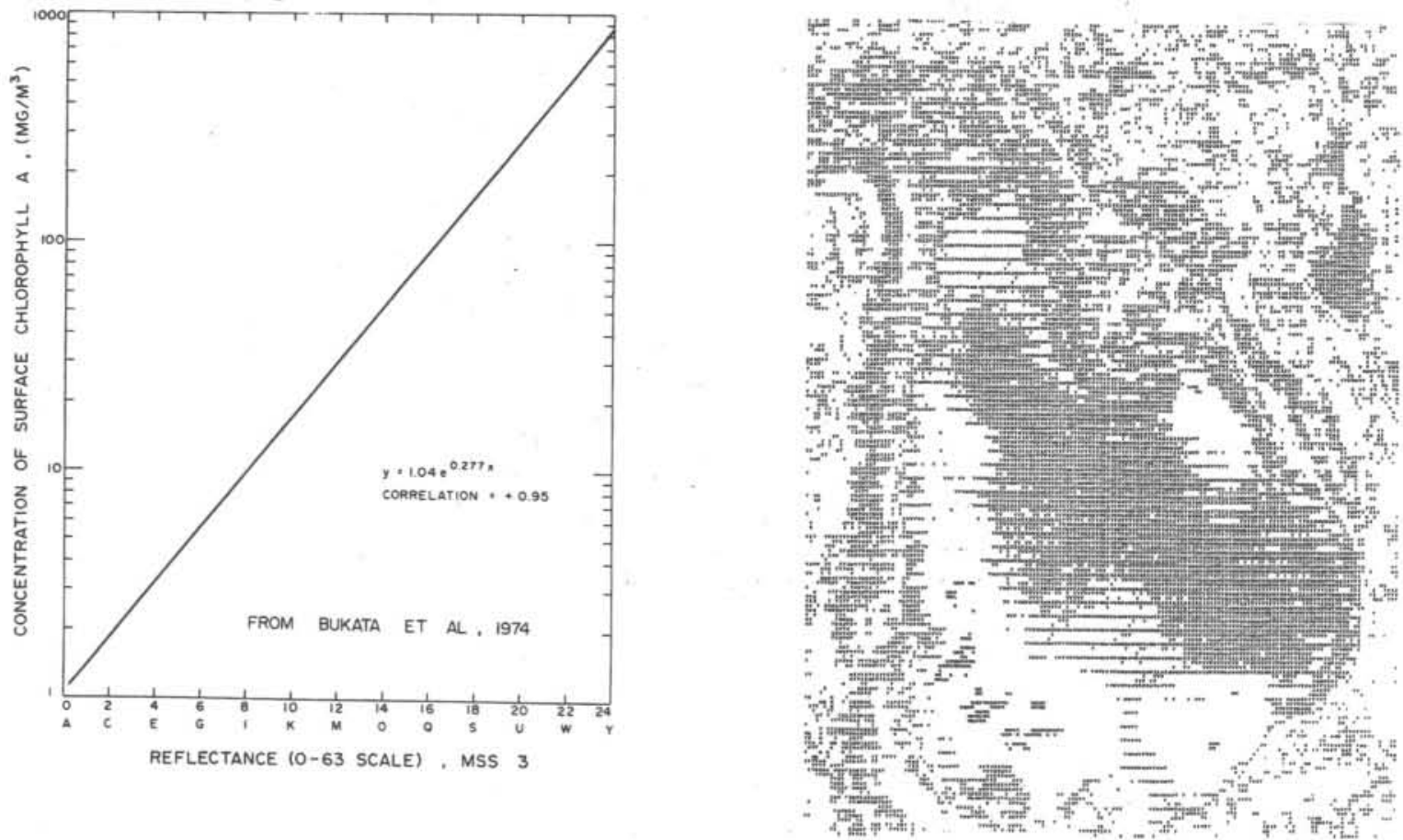

Fig. 4. Relative Measurements of Chlorophyll A, September 4, 1973. Transposing an example from Lake Erie, the OCT map of quantitative chlorophyli A was produced showing the general area of the lake with high concentration $(V, W, S)$ and ten centers of low concentration $(\mathbb{N})$. 

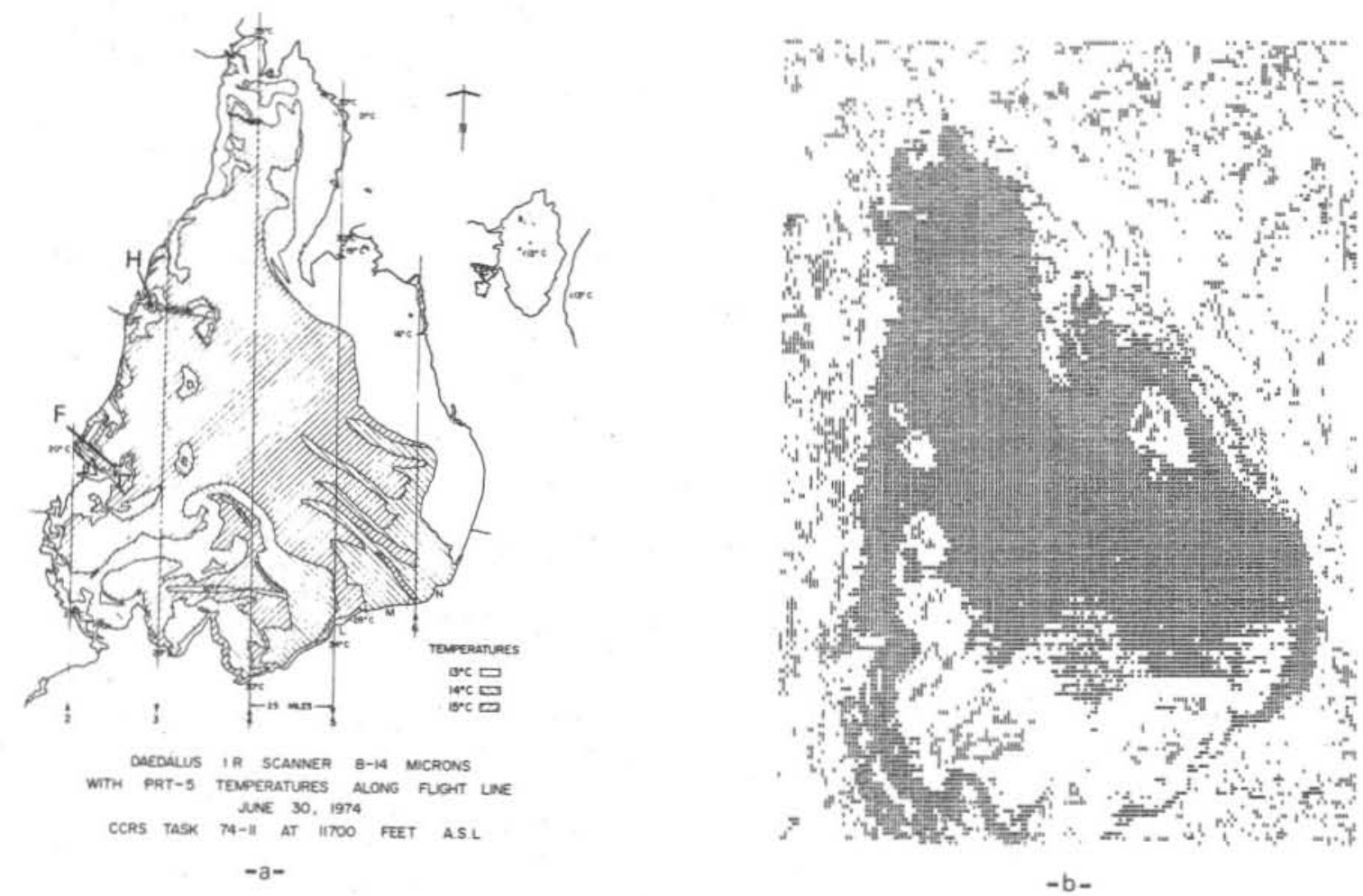

Fig. 5. Infrared scanning shows similar anomalies as the ERTS, September 4, 1973. The ERTS MSS 1 shows the dynamic situations better than any other band. The ten anomalies shown in Figure 3 are clearly shown in this ERTS frame(labelled quantitative as S or 18 in the relative reflectivity scale of 63 ). 